\title{
Why Hasn't This Patient Been Screened for Colon Cancer? An Iowa Research Network Study
}

\author{
Barcey T. Levy, PhD, MD, Terri Nordin, MD, Suzanne Sinift, MA, \\ Marcy Rosenbaum, PhD, and Paul A. James, MD
}

Background: Less than half of eligible Americans have been screened for colorectal cancer (CRC). The objective of this study was to describe physicians' reasons for screening or not screening specific patients for CRC and their approach to CRC testing discussions.

Methods: This study used mixed-methods. Physicians described their reasons for screening or not screening 6 randomly chosen patients who were eligible for CRC screening ( 3 screened and 3 not screened) whose CRC testing status was ascertained by medical record review. Verbatim transcripts from physicians responding to structured interview questions were used to identify themes. Specific elements of discussion were examined for their association with each physician's screening rate. Fifteen randomly chosen Iowa family physicians from the Iowa Research Network stratified by privileges to perform colonoscopy, flexible sigmoidoscopy, or neither procedure dictated the reasons why 43 patients were screened and 40 patients were not screened.

Results: Reasons patients were not up to date fell into 2 major categories: (1) no discussion by physician (50\%) and (2) patient refusal (43\%). Reasons for no discussion included lack of opportunity, assessment that cost would be prohibitive, distraction by other life issues/health problems, physician forgetfulness, and expected patient refusal. Patients declined because of cost, lack of interest, autonomy, other life issues, fear of screening, and lack of symptoms. Patients who were up to date received (1) diagnostic testing (for previous colon pathology or symptoms; $56 \%$ ) or (2) asymptomatic screening (44\%). Physicians who were more adamant about screening had higher screening rates $(P<.05$; Wilcoxon rank sum $)$. Physicians framed their recommendations differently ("I recommend" vs "They recommend"), with lower screening rates among physicians who used "they recommend" $(P=.05$; Wilcoxon rank sum).

Conclusions: Reasons many patients remain unscreened for CRC include (1) factors related to the health care system, patient, and physician that impede or prevent discussion; (2) patient refusal; and (3) the focus on diagnostic testing. Strategies to improve screening might include patient and physician education about the rationale for screening, universal coverage for health maintenance exams, and development of effective tracking and reminder systems. The words physicians choose to frame their recommendations are important and should be explored further. (J Am Board Fam Med 2007;20:458-468.)

Colorectal cancer (CRC) is the second leading cause of cancer death, ${ }^{1}$ with a person's lifetime risk

This article was externally peer reviewed.

Submitted 28 February 2007; revised 8 June 2007; accepted 13 June 2007.

From the Department of Family Medicine (BTL,TN, SS,MR,PAJ) and the Office of Consultation in Research in Medical Education (MR), Roy J. and Lucille A. Carver College of Medicine; and the Department of Occupational and Environmental Health, College of Public Health (PAJ), University of Iowa, Iowa City.

Funding: The authors would like to acknowledge support from the University of Iowa Department of Family Medicine, the Agency for Healthcare Research and Quality, grants R21 HS014490 (funded under the NCI/AHRQ PAR on Colorectal Cancer Screening in Primary Care Practice) and R21 HS013581, and the Department of Health and Human Resources, Health Resources and Services Administration, grant D12 HP00028. The project was initiated, designed, and analyzed by the manuscript authors. Terri Nordin was supported by the Doris Duke Charitable Foundation Clinical Research Fellowship Program for Medical Students (grant number 2004057) and the University of Iowa, Department of Family Medicine. being close to $6 \% .^{2}$ CRC screening allows for the detection and treatment of precancerous polyps and early-stage cancer. If detected early, $76 \%$ to $90 \%$ of cases of CRC can be either prevented or cured. ${ }^{3}$

Despite the availability of various screening modalities and protocols, fewer than half of all adults age 50 and older are up to date with screening for CRC. ${ }^{1,4,5}$ Depending on the population and definitions for screening, studies using self-reported

Conflict of interest: none declared.

Prior presentation: This work has been presented in part at the 2006 North American Primary Care Research Group Conference, October 15-18, 2006, and the 2007 Agency for Healthcare Research and Quality Practice-Based Research

Networks Research Conference, May 16-18, 2007.

Corresponding author: Barcey T. Levy, $\mathrm{PhD}, \mathrm{MD}$, Department of Family Medicine, 01292E Pomerantz Family Pavilion, 200 Hawkins Drive, University of Iowa, Iowa City, IA 52242 (E-mail: barcey-levy@uiowa.edu). 
data found screening rates in the United States either fall short of $50 \%^{1,4}$ or hover slightly above it. $^{6-11}$

Despite low screening rates for CRC, little is known about physicians' reasons for not screening specific patients. Discussions about CRC can be complex and time consuming because of the many possible screening methods and intervals. ${ }^{12,13} \mathrm{Al}-$ though physician recommendation is a key factor associated with screening, ${ }^{5,14-16}$ little is known about effective discussion strategies for CRC screening ${ }^{17}$ and discussion does not always lead to screening. ${ }^{17-19}$ General reasons physicians cite for not recommending cancer screening tests include provider forgetfulness, lack of time, inconvenience/logistic difficulties, and patient discomfort/refusal. ${ }^{20}$

Previous studies have used patient or physician focus groups to learn about general barriers to colorectal cancer screening. It is important to understand factors influencing screening for specific patients because CRC is potentially preventable and several practice guidelines and quality measures recommend CRC screening for eligible patients. ${ }^{12,13,21}$ This is the first study to identify factors influencing screening for specific, randomly chosen patients whose screening status was ascertained by detailed medical record review. We also examined physicians' general approach to screening discussions with patients.

\section{Methods}

This mixed-methods study was done as a part of a larger, cross-sectional study about CRC screening that related the screening status of 511 rural patients as documented in their medical records to patient and physician perceptions and characteristics. ${ }^{5}$ Recruitment of patients and physicians was described previously. ${ }^{5}$ Briefly, a stratified, random sample of 16 physicians from separate practices was selected for a cross-sectional study of CRC screening patterns from 57 Iowa Research Network physicians who were interested in participating in a general study on CRC screening. Physicians were stratified based on whether they had privileges to perform colonoscopy, flexible sigmoidoscopy, or neither procedure. Sixty patients aged 55 to 80 years (half men and half women) were randomly selected from each physician's practice and invited to participate in the cross-sectional study in 2004.
Although the guidelines are consistent that screening should begin at age 50 for patients at average risk, we selected a minimum age of 55 years so that there was no question that the patient should have been screened. Patient subjects completed a detailed mailed survey about past preventive screening and gave permission for their medical records to be reviewed. For each patient, we determined whether they were up to date with national CRC screening guidelines ${ }^{12,13}$ based on a detailed medical record review. Consistent with American Gastroenterological Association and American Cancer Society guidelines, ${ }^{12,13}$ "up to date" was defined as any of the following: 5 take-home hemoccult tests (fecal occult blood test), barium enema, or flexible sigmoidoscopy within 5.5 years or colonoscopy within the previous 10.5 years. An extra 6 months was allowed to provide some flexibility with the guidelines. A total of 511 patients $(53 \%$ of those invited) of 16 physicians gave their Informed Consent and had their medical records reviewed. The University of Iowa Institutional Review Board approved the study. All participating physicians and patients gave their informed consent.

\section{Physician Interview Questions}

Physician interview questions were developed by the authors using an iterative process that took place over several months. They were discussed at multiple research meetings, which included project staff and other members of the University of Iowa Department of Family Medicine. After several iterations, the interview questions and protocol were piloted with 3 practicing family physicians not participating in the study. These physicians were affiliated with one of the outlying offices of the department. Physician responses indicated good face validity.

Interview questions were mailed to physicians in 2004 and early 2005 (Appendix 1), along with the names of 6 randomly selected patients, 3 who were up to date with CRC screening guidelines and 3 who were not, based on our detailed medical record review. For each patient, the physician was asked to explain what factors either led to or prevented the patient from being screened. Physicians were also asked to describe their general approach to screening and their preferred screening test. Physicians called a toll-free number available 24 hours a day to audiotape their responses into the VoiceGuide $\mathrm{v}$ 4.9.0 recording software (Katalina Technologies 
Propietary Ltd., Sydney, Australia). This method of data collection was used because of its convenience for the physicians and their familiarity with dictation. Each set of responses to the interview questions was transcribed verbatim.

\section{Qualitative Analysis}

Four members of the research team, a medical anthropologist trained in qualitative methods, a practicing family physician, and 2 research assistants with experience in qualitative analysis used an editing analysis approach to develop a codebook consisting primarily of codes that emerged after iteratively reading the interview transcripts and reaching a point of data saturation. ${ }^{22,23}$ Interviews were coded individually by the research assistants using this codebook and then compared to reach consensus of code definitions. N'vivo software (QSR International, Victoria, Australia) was used to code all the transcripts and then to group codes into salient themes. The major themes that emerged were (1) reasons individual patients were up to date, (2) reasons individual patients were not up to date, (3) screening test preferences, and (4) general approaches to CRC screening. These major themes, and any categories within the themes, were compared by the other researchers to make sure the narrative agreed with the identified theme or until a consensus was reached. As the analysis progressed, the theme "reasons patients were up to date" emerged with 2 different attributes: (1) diagnostic testing or (2) asymptomatic screening. Here diagnostic testing refers to tests done to evaluate symptoms or as surveillance examinations to follow up on previous colon pathology. Asymptomatic screening refers to being tested in the absence of symptoms or pathology, and includes those patients with a positive family history who were tested. Similarly, for patients who were not up to date, 2 other categories emerged focusing on whether screening was discussed.

\section{Quantitative Analysis of Elements of General Approaches}

Within the theme "General approaches to CRC screening," the following discussion elements were each grouped into one of 2 categories (present or absent) based on content: (1) degree of adamancy, (2) use of "I recommend" or "They recommend," (3) use of concrete examples, and (4) the use of objective, numerical data. The degree of adamancy ranged from discouraging, to neutral, to giving a personal recom- mendation, to strongly advocating CRC screening. Discussion elements often overlapped. Using the screening rate for each physician as determined in the larger cross-sectional study, ${ }^{5}$ we examined whether these discussion elements were related to screening rates using the Wilcoxon rank sum test.

\section{Results}

Fifteen of the 16 physicians (94\%) who completed the cross-sectional study completed this qualitative study with usable data. Of these physicians, 6 performed colonoscopy, 4 performed flexible sigmoidoscopy, and 5 performed neither procedure. Fourteen physicians were men, the average age was 53 years (range, 43-69 years), the average length of time in practice was 21.6 years, and they had an average of 5.5 partners within their practices (range, 1-15). All were board-certified family physicians working in predominantly rural settings with a median population of $6,112 .{ }^{24}$ The percentage of patients accepting the mailed invitation to participate in the larger study ranged from $31 \%$ to $68 \%$ by physician, with a median acceptance rate of $51 \%$. The percentage of patients who were up to date with CRC screening guidelines in the larger study ranged from $5 \%$ to $75 \%$, with a median physician-specific rate of $41 \%$.

Physicians dictated responses for a total of 43 patients who were up to date and 45 patients who were not. (One physician only had 1 patient who was up to date and that is why there are only 43 patients for this portion of the qualitative analysis.) Of the 45 patients not considered up to date based on our detailed review of medical records, 5 patients were excluded from analysis because physicians reported either they had been screened in other offices. For 3 of these patients, physicians stated the results were overlooked during chart review; 1 patient's test was done 8 days before our chart review and the results were not available for the chart review; and 1 patient told the office a test had been done, but there was no actual record of the test. This left a total of 40 patients who were not up to date. The level of agreement for discussion of CRC screening (Yes/No) between the physician narrative and the medical record review was $68 \%$ and there was no significant difference between the physician narrative and the medical record review (McNemar's test; $P>.05$ ). All of the reasons physicians discussed for why patients were 


\begin{tabular}{|c|c|}
\hline Reasons & Illustrative Quotation \\
\hline \multicolumn{2}{|l|}{ Reasons for diagnostic testing } \\
\hline Symptoms suggestive of possible CRC & $\begin{array}{l}\text { He did have one episode of bleeding and I worked on him for about } 2 \text { years } \\
\text { to bave a colonoscopy. }\end{array}$ \\
\hline Previous pathology within the colon & $\begin{array}{l}\text { He actually had had rectal bleeding back in 1993, and I did a flex sig..., } \\
\text { and I found a polyp... So actually what got bim started on the trail of } \\
\text { lower GI endoscopy was symptoms more than anything else, and be's just } \\
\text { followed through as he was instructed with surveillance scopes. }\end{array}$ \\
\hline \multicolumn{2}{|l|}{ Reasons for asymptomatic screening } \\
\hline Physician recommendation to be screened & $\begin{array}{l}\text { She actually presented for a bealth maintenance examination in } 2002 \text { and } \\
\text { [we]. . actually recommended that she be screened for colon cancer. She } \\
\text { accepted the recommendations and then chose the colonoscopy as the } \\
\text { method of choice. }\end{array}$ \\
\hline \multirow[t]{2}{*}{$\begin{array}{l}\text { Patient awareness of and interest in screening and } \\
\text { health maintenance }\end{array}$} & $\begin{array}{l}\text { [She] did have a screening test because she understands the importance of } \\
\text { it. }\end{array}$ \\
\hline & $\begin{array}{l}\text { [He] has been a long-time patient who bas been interested in regular } \\
\text { bealth supervision examinations and chronicity of care examinations. }\end{array}$ \\
\hline Patient has/had a type of cancer other than CRC & $\begin{array}{l}\text { [She] had had breast cancer times two. I advised her there was an } \\
\text { association between breast cancer and colon cancer and I personally had } \\
\text { two cases where this was the case, and this was the motivation for her to } \\
\text { move forward with the colonoscopy. }\end{array}$ \\
\hline Family history of CRC & $\begin{array}{l}\text { During [ his] well care we discussed risk factors. . . . He had a positive } \\
\text { family bistory of colon cancer. }\end{array}$ \\
\hline $\begin{array}{l}\text { Multiple factors (family history, physician } \\
\text { recommendation, patient awareness) }\end{array}$ & $\begin{array}{l}\text { Basically, her mom had colon cancer, and she actually is clever enough to } \\
\text { figure out what we mean when we talk about screening tests. I think she } \\
\text { basically just took my advice and decided to go abead and have a } \\
\text { screening test. }\end{array}$ \\
\hline
\end{tabular}

CRC, colorectal cancer; GI, gastrointestinal.

or were not up to date are included in Tables 1 and 2, along with illustrative quotations for each reason.

\section{Physicians' Reasons for Specific Patients Being Up to Date ( $n=43$ patients) (Table 1)}

Factors Leading to Diagnostic Testing

Once the study was underway, we realized that many patients received testing in response to symptoms or for previous pathology, and that they were not "screened" in the strict sense of the word. The majority $(\mathrm{n}=24 ; 56 \%)$ received their most recent test because of a symptom that could be suggestive of possible colon cancer $(n=15)$ or a history of previous pathology in the colon $(\mathrm{n}=9)$. Symptoms that triggered testing included abdominal pain, rectal bleeding, constipation, or change in bowel habits. Previous pathology included past diagnoses of colon cancer, polyps, inflammatory bowel disease, and diverticulitis; of the 9 with previous pathology, 7 had originally had a colon study done in response to symptoms.

\section{Factors Leading to Asymptomatic Screening}

Among the 19 patients who were screened in the absence of symptoms, 4 main factors surfaced: (1) physician recommendation, (2) patient awareness, (3) positive family history, and (4) a previous diagnosis of cancer other than colon cancer.

Physicians explicitly stated that their recommendation was the impetus for 17 of 19 patients to be screened in the absence of other risk factors. Recommendations that led to screening occurred in the context of health maintenance exams in 6 of 19 cases. Three patients were screened because of a previous diagnosis of cancer other than colon cancer. Physicians noted that some patients were up to date because of discussions regarding the patients' family histories of colon cancer. Several factors often occurred together and provided added momentum for a patient to be screened.

\section{Physicians' Reasons for Specific Patients Not Being Up to Date ( $n=40$ patients) (Table 2)}

Factors That Hindered Screening Discussions

Of the 40 patients who were not up to date, physicians reported not discussing screening with 20 of them $(50 \%)$; for 3 other patients it was unclear from the physician narrative whether a discussion had occurred. 
Factors that hindered screening discussions

Lack of opportunity to discuss screening

Patients came in only for acute visits or problems

Patients came in sporadically or saw other providers for health maintenance care

No tracking system

Not enough time during appointments

Physician forgetfulness

Assessment that cost or lack of insurance would be prohibitive to patient

Patient had life issues or other health problems that distracted from screening

Expected patient refusal and/or lack of interest

When CRC screening was discussed, but patient declined Cost of screening tests

Lack of interest in screening

Patient autonomy

Patients had life issues or other health problems

Fear of screening test procedure

No symptoms or family history of CRC
[The patient] has always been a very acute care oriented patient and probably has only come to see me on maybe 3 occasions over the past 15 years. Hence, again, his inconsistent seeking of health care has led to failure to screen for colorectal cancer.

He gets his physicals at the VA hospital, so I really haven't considered myself in the position to offer him screening [since] I don't do [bis] routine physicals, [which] is when I bring up this subject.

She generally presents for acute care, and honestly with ... the intermittent few times I see her, I forgot to even bring up colorectal cancer screening. And so, I would put ber down as an office system issue with no reminder tracking system.

I think the reason that he wasn't screened, and probably several other [patients], was just a matter of time in not getting everything done.

See quote above for "no tracking system"

Anyway, the bottom line is he doesn't have any insurance and he doesn't have any money, and he's a truck driver kinda just barely scraping by.

So, basically, we're distracted and he's distracted by other [health] problems. I don't believe I've ever really pushed getting colon cancer screening.

He has no complaints, and I would suspect that he doesn't think that it is necessary, and he's not one that reads papers or talks about health care. I don't believe I've ever really pushed getting colon cancer screening 'cause I didn't think be would probably be real keen on it.

[She] won't do it because she doesn't have the finances and doesn't have insurance [that] will pay for the procedure.

I think basically he's just your proverbial older rural Iowa retired farmer guy who kind of likes to leave things well enough alone ... and so I'm not too surprised if he doesn't do everything that I tell bim to do. [He] has not been screened because he bas no interest in health prevention.

His father actually died of colon cancer. I discussed this with him during a visit in 3/02, and be personally refused to undergo any type of screening. He's a clinical psychologist which means that be's actually given more latitude in running his own health care under the assumption that he has more inside information about bealth care, which may or may not actually be very true. The plan for bim is to bring up colon cancer screening again in the future when he is here for an unrelated visit or perhaps a bealth maintenance visit.

Her husband had recently died. She had a depressive reaction associated with it and did not think it was necessary to do the screening.

She was not screened and $\ldots$ is resistant to have the colonoscopy due to the fear of the procedure.

$[\mathrm{He}]$ has not been screened because he has no interest in . . . having a colonoscopy done unless he was having some symptoms that would require it.

CRC, colorectal cancer.

Physicians shared many reasons for not discussing CRC screening with their patients, with the most common being a perceived lack of opportunity to have such a discussion. Lack of discussion about CRC screening often happened because patients came in only for acute health issues, patients came in very sporadically, a lack of a tracking system prevented the physicians from remembering to 
discuss screening with their patients, or a lack of time to discuss screening. In some cases, physicians made the assessment that patients would refuse because of either financial concerns or a perceived lack of interest in health and screening.

\section{Factors Leading to Specific Patients Declining Screening}

Physicians reported discussing CRC screening with 17 of the 40 (43\%) patients who either overtly refused or more passively declined to be screened. Among these 17 patients, the most commonly reported physician-perceived reasons patients declined screening included a concern about cost, the lack of patient interest in screening, the presence of confounding life issues or other health problems, fear of the testing procedure, and patients' lack of worrisome symptoms or a family history of CRC. Patient fears were noted primarily in conjunction with colonoscopy and flexible sigmoidoscopy. Finally, physicians indicated that patients perceived their risk was low in light of a negative family history and the absence of symptoms. Because of a combination of the factors mentioned above, some patients may have declined CRC screening even when their risk for the disease was elevated in light of a positive family history.

\section{Physicians' Preferred CRC Screening Tests}

When discussing CRC screening with their patients, physicians usually reported favoring a specific screening method. Eleven of the 15 physicians (73\%) preferred colonoscopy because of its accuracy, the ability to remove polyps, and the long interval between tests.

I encourage patients to receive a colonoscopy. Most pathology over the years we have found has been beyond the reach of flexible sigmoidoscopy, and because patients are reluctant to bave colon examinations in general, doing an examination less often is more practical, as well as being a more complete examination.

The 3 physicians who did not state a preference for using colonoscopies preferred the fecal occult blood test because of its low cost and convenience:

Here in [small town] Iowa, there's a lot of underinsured or absolutely poor people, and it gets to be a mind-set, I guess, to [use] one of the more frugal tests. That's why I prefer the fecal occult blood testing-again, low hassle, low cost, private, and readily available to anybody of any insurance status or income level.

My primary effort, including [that of] my nurses, is to encourage all patients to have a Hemoccult series at any general examination for any purpose. I realize that the accuracy is limited, but it does get patients used to learning about colorectal cancer and screening for colorectal cancer. If patients have any Hemoccult card that is positive, we strongly urge colonoscopy as the gold standard.

Despite these clear preferences, the 19 patients who received asymptomatic screening had a variety of screening tests. Eleven patients received colonoscopy, 4 received fecal occult blood testing, 3 received a combination of barium enema and flexible sigmoidoscopy, and 1 patient received a flexible sigmoidoscopy.

\section{Overall Patterns of Discussions About CRC Screening}

Physicians were asked to provide a typical example of what they might say to a patient at average risk for CRC who needs screening. Responses were highly variable in content and degree of adamancy for CRC screening. The degree of adamancy for CRC screening ranged from being discouraging, to neutral, to clearly advocating (examples are shown in Table 3).

During discussions regarding screening, physicians also used a variety of strategies to motivate their patients to be screened. Some physicians used objective facts and numerical evidence to convince their patients of the importance of screening.

I typically... say to them, 'Based on age, that there is a concern. . . after the age of 50 . . of developing colon polyps and colon cancer.'

Every 5 years you should be screened for colon cancer... [because] 1 out of 18 or 19 men and women will end up getting colon cancer in their lifetime.

Other physicians attempted to persuade patients to be screened by showing enthusiasm and by using easily understood, relevant examples to provide a rationale for a positive outcome:

I say, 'We're out to screen everyone over age 50 for colon cancer because we consider it a preventable disease.' I tell people, 'If we could take all the polyps 
Table 3. Overall Patterns of CRC Screening Discussions

\begin{tabular}{|c|c|}
\hline Descriptor & Illustrative Quotation \\
\hline Discouraging & $\begin{array}{l}\text { On the other band, you probably } \\
\text { don't have colon cancer and, } \\
\text { therefore, there's a real good } \\
\text { chance that doing this } \\
\text { screening test won't benefit } \\
\text { you in any way other than } \\
\text { giving you the peace of mind } \\
\text { that you don't have something } \\
\text { that you weren't even } \\
\text { suspicious of. }\end{array}$ \\
\hline $\begin{array}{l}\text { Neutral recommendation/ } \\
\text { outside influence }\end{array}$ & $\begin{array}{l}\text { If the patient is } 50 \text { years old or } \\
\text { more, I just simply suggest } \\
\text { that the American Cancer } \\
\text { Society and the American } \\
\text { Society of Gastroenterologists } \\
\text { suggest that all patients at } 50 \\
\text { years of age or older should be } \\
\text { screened for colorectal cancer. }\end{array}$ \\
\hline Personal recommendation & $\begin{array}{l}\text { We would recommend, after the } \\
\text { age of } 50 \ldots \text { you be screened } \\
\text { for colon cancer. }\end{array}$ \\
\hline Champion & $\begin{array}{l}\text { I'd say, 'It's imperative that a } \\
\text { screening colonoscopy be } \\
\text { done. . ' I tell patients myself } \\
\text { that I believe in this and } \\
\text { when I turn } 50 \text {. . I myself } \\
\text { will have a colonoscopy. } \\
\text { 'The lifetime incidence of colon } \\
\text { cancer approaches } 8 \% \text { in this } \\
\text { country. If you were to cross } \\
\text { the street and get run over } 1 \\
\text { out of } 10 \text { times, which is } \\
\text { essentially the same [risk], } \\
\text { you would consider that a } \\
\text { significant risk, so I think we } \\
\text { ought to take a look [and do a } \\
\text { colonoscopy].' And sometimes I } \\
\text { tell them that my father and } \\
\text { my grandmother had colon } \\
\text { cancer and that I'm an } \\
\text { evangelist on the subject. }\end{array}$ \\
\hline
\end{tabular}

out of all the patients, there would be no more colon cancer.'

If you catch it early, you can definitely be cured of it and not have further problems... . If you don't catch it early, you're probably not going to be curable.

Using the physician-specific rates of CRC testing from the cross-sectional study, ${ }^{5}$ we examined whether screening rates were related to specific elements of communication found in the narratives physicians gave for their CRC discussions. Higher screening rates were found among physicians who were more adamant about the need for screening; lower screening rates were found among physicians who framed their recommendation to patients as "they recommend" or "organization X recommends" versus some other phrasing (Wilcoxon rank sum test; $P \leq .050$ for each comparison). There was a trend toward higher screening rates among physicians who included themselves as making the recommendation ("I recommend" or "we would recommend" vs those who used "they recommend") (Wilcoxon rank sum test; $P=.079$ ), although not all physicians used one of these terminologies. No relationship was found between screening rates and the use of either objective data or easily understood examples in the narratives.

Thirteen of the 15 physicians thought that it would be helpful to have someone in the office determine screening status and place this on the chart. The other 2 physicians mentioned already having a flow sheet for preventive services that was not always kept up to date.

\section{Discussion}

Although it is well known that the majority of people at risk for CRC are not screened, ${ }^{1,4-10}$ this is the first study to ask physicians why they had not screened specific patients. Understanding reasons why specific patients have not been screened is important because although there is much literature that stresses the importance of physician recommendation for CRC screening and the need for shared decision making, ${ }^{17,25-27}$ there is very little about the relationship of specific communication strategies to screening rates.

Reasons specific patients were not up to date with testing fell into 2 broad categories: (1) lack of discussion (50\%) and (2) patient refusal (43\%). Over half of the patients who were up to date received diagnostic testing as opposed to asymptomatic screening. We found evidence that the words physicians use to present their recommendation for screening potentially impacts whether patients follow through with testing, based on higher physician-specific screening rates among physicians whose narratives demonstrated they were more adamant about screening and lower rates when physicians used terms like "they recommend" or "organization X recommends." There may be subtle, important nuances between the physician passing on a recommendation from a professional organization ("they recommend") and the physician's personal recommendation that supports and promotes screening ("I recommend"), which should be explored in future studies. 
Physicians provided many reasons for not discussing CRC testing, with the most common being lack of opportunity for discussion. Lack of opportunity resulted from many factors related to the health care system, patient, and physician, which included patients who presented only for acute problems or sporadically, patients who saw other providers for health maintenance, lack of a tracking system, time pressures during appointments, and physician forgetfulness. In some cases, the patient had other life issues or health problems that distracted from screening or physicians made the assessment that costs would be prohibitive to the patient or expected that the patient would refuse.

Other studies have focused on the general reasons physicians give for lack of screening and include reasons similar to those found in this study (lack of time, forgetfulness, concern about patient acceptance, concern about costs, and low probability of detecting significant lesions). ${ }^{19,20,28-30}$ The reasons perceived by physicians in this study often mirrored those reported by patient focus groups, including lack of patient interest in screening ${ }^{31}$ and low perceived relevance. ${ }^{18,31,32}$

\section{Implications}

This study provides new insights into the use of CRC screening in busy, rural primary care settings. The importance of physician discussion and recommendation for screening has been underscored in this and other studies. ${ }^{5,8,14-17}$ Taking action to increase rates of CRC discussion is worthwhile because performing routine CRC screening on patients of average risk starting at age 50 has the potential to prevent or cure many cases of CRC in the United States. ${ }^{3}$ Screening for CRC is an extensive process that goes beyond simply ordering a test. The process of building rapport, conducting screening discussions, and supporting the patient's decision was highly personalized to each individual patient and often took place over many visits by the family physicians in this study. Among the patients who were up to date with guidelines, the majority (56\%) of patients had a CRC test done in response to worrisome symptoms or as surveillance for previously identified pathology rather than for asymptomatic screening. This is concerning given that the vast majority $(75 \%)$ of CRC cases occur in people who do not have risk factors. ${ }^{1}$ Most physicians felt their recommendation was key for their patients who had been screened.
Because many CRC tests were ordered for diagnostic testing, patient and physician education needs to include the concept that CRC screening is recommended for everyone over the age of $50 \mathrm{be}$ fore symptoms develop. Although some physicians may need to be reminded that preventive screening is "the examination of asymptomatic people to classify them as likely or unlikely to have the disease that is the object of screening," 33 it is more likely that systems need to be implemented that remind physicians and staff that screening is due. ${ }^{34}$ Symptoms may prompt patients to see their physician and clinicians may feel patients are more likely to agree to be tested if symptoms are present. Authors and organizations reporting CRC testing rates should attempt to distinguish between diagnostic testing and asymptomatic screening rates.

Universal coverage for health maintenance exams (to allow the time and opportunity needed for appropriate patient education and screening discussions) would facilitate screening, as would universal coverage for CRC screening tests and any needed follow-up. It is interesting that in some cases physicians made the assessment that their patients would refuse screening and did not offer it. For medical legal reasons and for quality patient care, all eligible patients need to be advised that CRC screening tests are available and recommended by major organizations, and this discussion must be documented in the medical record. Physicians and their patients may also benefit from the support of a preventive tracking system to document discussions regarding screening and dates of specific tests. This has been demonstrated in the Veterans Administrative system, where CRC screening rates approaching $80 \%$ have been reported. ${ }^{35}$ Several measures of ambulatory care quality include CRC screening rates, ${ }^{21,36,37}$ and the American Public Health Association's recently adopted policy also encourages CRC screening. ${ }^{38}$ Quality measures should take into account the importance of the physician providing the patient with appropriate education and adequate discussion, and of rewarding physicians for incorporating these into their practice. Given that physicians would need to spend 7.4 hours per working day to provide recommended preventive services to an average patient panel, ${ }^{39}$ it is important for regulatory bodies to recognize the physician's time needed to make preventive recommendations. Reported rates should exclude patients who have declined screening after 
a documented discussion. Although these physicians generally preferred colonoscopy, they may need to increase use of fecal occult blood testing in patients for whom cost and fear of endoscopy are major issues.

Future research is needed to develop successful patient and physician education programs for CRC screening and to identify and implement effective tracking and chart reminder systems. Because primary care physicians often have a long, continuous relationship with patients, future studies should address the accuracy of their assessment of patient desires regarding screening. Further work is also needed to identify effective elements of physician recommendations and which types of communication strategies work best for specific patients. The results presented here may provide a guide for researchers to observe or record actual doctorpatient conversations to further examine physicians' approaches to screening.

\section{Strengths and Limitations}

Although a few studies have examined barriers and facilitators to CRC screening from the patients ${ }^{20,31,40-42}$ or physicians ${ }^{30,42-45}$ perspective using focus groups, interviews, or surveys, no other study has examined how physicians make decisions about screening specific patients eligible for screening randomly chosen from their practice. Nor are we aware of any study that has examined screening rates and their association with specific elements of the screening discussion. Limitations include that patients and physicians entered into this study knowing it was about CRC screening, so these results may not be applicable to the general population of patients seeing primary care physicians. Selection bias is a limitation in any study that requires informed consent, but we randomized the selection of both patients and physicians to minimize this potential bias. The data were collected in 2004 to 2005, when national guidelines recommended screening for average risk people 50 years of age or older. ${ }^{12,13}$ Medicare began covering annual 3 card fecal occult blood tests, flexible sigmoidoscopy, and barium enemas for screening 1 January 1998 and colonoscopy was added 1 July 2001 for asymptomatic people. ${ }^{46}$ Thus, it would not have been necessary for physicians to use diagnoses for Medicare coverage, although there may have been some holdover from previous practice patterns. Because physicians do not typically doc- ument the reasons why patients refuse screening tests, we do not know whether the physician assessments about reasons for potential patient refusal were accurate. However, we found a $68 \%$ agreement between the narratives and the medical record reviews for whether a discussion took place; the level of detail provided in the narratives suggests that these physicians knew the patients and their circumstances quite well. Ideally, the CRC screening decision should involve shared decision making and allow for patient refusal. We did not tape actual physician-patient discussions, but rather relied on the physician to audiotape their reasons for screening or not screening a specific patient while referring to the medical record. This method was used for its convenience for physicians and the well-recognized difficulty in setting up telephone interviews. It did not allow for probing responses to specific questions. Because the majority of these Iowa Research Network physicians practiced in a rural environment in the United States, these findings may not be generalizable to other practice settings.

\section{Conclusion}

This study provides new evidence from the physicians' perspective for why many patients remain unscreened for CRC. Reasons include the lack of discussion because of factors related to the health care system, patient, and physician; patient refusal; and the focus on diagnostic testing. The words and manner physicians use to discuss CRC screening may influence patients and should be explored further. Strategies to improve screening should include education for both physicians and patients about the rationale for screening, universal coverage for health maintenance exams, and developing effective tracking and reminder systems. Future work should address ways to optimize physicians' communication strategies.

\section{Appendix 1. Interview Questions Patient-specific Questions}

$1-3$. Based on our chart review conducted on $<$ date $>$, it appears that $<$ patient name $>$ was not screened for CRC in the 5 to 10 year interval preceding our chart review date. What factors* led to $<$ patient name $>$ not being screened for CRC? 4-6. Based on our chart review conducted on $<$ date $>$, it appears that $<$ patient name $>$ received a 
$<$ CRC test type $>$ test on $<$ date $>$. What factors led to $<$ patient name $>$ being screened with a $<$ CRC test type $>$ test?

\section{General Questions}

7. Pretend that you are talking with a patient at average risk for CRC who needs screening for CRC. Please provide a typical example of what you might say to this patient.

8. A. Do you feel that you give equal weight to the options you present or do you encourage patients to obtain a specific type of screening test?

B. If you encourage a specific type of screening test, please tell which you prefer and why.

* By factors, we mean any clinically relevant factors the patient may have, including psychological, social, or economic factors that may have influenced you, office system issues such as no reminder or tracking system, or that you disagree with the guideline for this particular patient and why.

We would like to thank the Iowa Research Network physicians for their participation in the study.

\section{References}

1. American Cancer Society. Colorectal cancer facts and figures special edition 2005. Atlanta (GA): American Cancer Society; 2005.

2. American Cancer Society. Cancer facts and figures 2002. Atlanta (GA): American Cancer Society; 2002.

3. Winawer S, Zauber AG, Ho MN, et al. Prevention of colorectal cancer by colonoscopic polypectomy. The national polyp study workgroup. [see comment]. N Engl J Med 1993;329:1977-81.

4. Centers for Disease Control and Prevention. Trends in screening for colorectal cancer-United States, 1997 and 1999. MMWR 2001;50:162-6.

5. Levy BT, Dawson J, Hartz AJ, James PA. Colorectal cancer testing among patients cared for by Iowa family physicians. Am J Prev Med Sep 2006;31:193201.

6. Straus W, Mansley EC, Gold KF, Wang Q, Reddy $\mathrm{P}$, Pashos CL. Colorectal cancer screening attitudes and practices in the general population: a risk-adjusted survey. J Public Health Manag Pract 2005;11: 244-51.

7. Yeazel M, Church TR, Jones RM, et al. Colorectal cancer screening adherence in a general population. Cancer Epidemiol Biomarkers Prev 2004;13:654-7.

8. Zapka J, Puleo E, Vickers-Lahti M, Luckmann R. Healthcare system factors and colorectal cancer screening. Am J Prev Med 2002;23:28-35.

9. Greiner K, Engelman KK, Hall MA, Ellerbeck EF.
Barriers to colorectal cancer screening in rural primary care. Prev Med 2004;38:269-75.

10. Centers for Disease Control and Prevention. Colorectal Cancer Test Use Among Persons Aged or $=50$ Years-United States, 2001. MMWR 2003;52:193-6.

11. Centers for Disease Control and Prevention. Increased use of colorectal cancer tests-United States, 2002 and 2004. MMWR 2006;55:308-11.

12. Rex D, Johnson DA, Lieberman DA, Burt RW, Sonnenberg A. Colorectal cancer prevention 2000: screening recommendations of the American College of Gastroenterology. Am J Gastroenterol 2000; 95:868-77.

13. Smith RA, von Eschenbach AC, Wender R, et al. American Cancer Society guidelines for the early detection of cancer: update of early detection guidelines for prostate, colorectal, and endometrial cancers. Also: update 2001-testing for early lung cancer detection. CA Cancer J Clin 2001;51:38-75; quiz 77-80.

14. Brawarsky P, Brooks DR, Mucci LA, Wood PA. Effect of physician recommendation and patient adherence on rates of colorectal cancer testing. Cancer Detect Prev 2004;28:260-8.

15. Klabunde CN, Vernon SW, Nadel MR, Breen N, Seeff LC, Brown ML. Barriers to colorectal cancer screening: a comparison of reports from primary care physicians and average-risk adults. Medical Care Sep 2005;43:939-44.

16. Wee CC, McCarthy EP, Phillips RS. Factors associated with colon cancer screening: the role of patient factors and physician counseling. Prev Med 2004;41:23-9.

17. Lafata JE, Divine G, Moon C, Williams LK. Patient-physician colorectal cancer screening discussions and screening use. Am J Prev Med Sep 2006; 31:202-9.

18. Davis T, Dolan NC, Ferreira MR, et al. The role of inadequate health literacy skills in colorectal cancer screening. Cancer Invest 2001;19:193-200.

19. Lemon SC, Zapka JG, Estabrook B, Erban S, Luckmann R. Screening for colorectal cancer on the front line. Am J Gastroenterol Apr 2003;98:915-23.

20. McPhee S, Richard RJ, Solkowitz SN. Performance of cancer screening in a university general internal medicine practice: comparison with the 1980 american cancer society guidelines. J Gen Intern Med 1986;1:275-81.

21. National Committee for Quality Assurance. Colorectal cancer screening: percentage of adults 50 to 80 years of age who had appropriate screening for colorectal cancer. HEDIS 2006. Health plan employer data \& information set. Vol 2, Technical specifications. Washington (DC): National Committee for Quality Assurance; 2005:350 p.

22. Crabtree B, Miller W. Doing qualitative research. 2nd ed. Thousand Oaks (CA): Sage Publications, Inc; 1999. 
23. Rice P, Ezzy D. Qualitative research methods: a health focus. Oxford: Oxford University Press; 1999.

24. U.S. Census Bureau. Profiles of general demographic characteristics. Available at: http://www. census.gov/prod/cen2000/dp1/2kh00.pdf. Accessed 6 March 2006.

25. Dolan JG. Patient priorities in colorectal cancer screening decisions. Health Expect Dec 2005;8:33444.

26. Myers RE. Decision counseling in cancer prevention and control. Health Psychol Jul 2005;24 Suppl 4:S71-7.

27. Rimer BK, Briss PA, Zeller PK, Chan EC, Woolf SH. Informed decision making: what is its role in cancer screening? Cancer 2004;101 Suppl 5:1214-28.

28. Levin B, Smith RA, Feldman GE, et al. Promoting early detection tests for colorectal carcinoma and adenomatous polyps: a framework for action: the strategic plan of the National Colorectal Cancer Roundtable. Cancer 2002;95:1618-28.

29. Taylor ML, Anderson R. Colorectal cancer screening: physician attitudes and practices. WMJ 2002; 101:39-43.

30. Sewitch MJ, Burtin P, Dawes M, et al. Colorectal cancer screening: physicians' knowledge of risk assessment and guidelines, practice, and description of barriers and facilitators. Can J Gastroenterol 2006; 20:713-8.

31. Beeker C, Kraft JM, Southwell BG, Jorgensen CM. Colorectal cancer screening in older men and women: qualitative research findings and implications for intervention. J Community Health 2000;25:263-78.

32. McCaffery K, Borril J, Williamson S, et al. Declining the offer of flexible sigmoidoscopy screening for bowel cancer: a qualitative investigation of the decision-making process. Soc Sci Med 2001;53:679-91.

33. Rothman K, Greenland S. Modern epidemiology. 2nd ed. Baltimore (MD): Lippincott-Raven; 1998.

34. Solberg LI, Kottke TE, Brekke ML, Conn SA, Magnan S, Amundson G. The case of the missing clinical preventive services systems. Eff Clin Pract 1998;1: 33-8.

35. Department of Veterans Affairs. VA Midwest Health Care annual report fiscal year 2005. Available at: http://www.iowa-city.med.va.gov/visn23/pubs/ FY05-Annual-Report.pdf. Accessed 1 June 2006.
36. Institute for Clinical Systems Improvement. Health care guideline: colorectal cancer screening. Eleventh Edition June 2006. Available at: http://www.icsi. org/colorectal_cancer_screening /colorectal_cancer_ screening_5.html. Accessed 1 June 2007.

37. Physician Consortium for Performance Improvement. Clinical performance measures: preventive care and screening. Tools developed by physicians for physicians. Chicago (IL): American Medical Association (AMA); 2005. 13 p. [11 references].

38. American Public Health Association. (2005). Colorectal Cancer Screening. Policy number 2005-11. Policy date 12/14/2005. Available at: http://www.apha.org/ advocacy/policy/policysearch/default.htm?id=1305. Accessed 1 June 2007.

39. Yarnall KS, Pollak KI, Ostbye T, Krause KM, Michener JL. Primary care: is there enough time for prevention? Am J Public Health. 2003;93:635-41.

40. Katz M, James AS, Pignone MP, et al. Colorectal cancer screening among African-American church members: a qualitative and quantitative study of patient-provider communication. BMC Public Health 2004;4:62.

41. Dube C, Fuller BK, Rosen RK, Fagan M, O’Donnell J. Men's experiences of physical exams and cancer screening tests: a qualitative study. Prev Med 2005; 40:628-35.

42. O'Malley A, Beaton E, Yabroff KR, Abramson R, Mandelblatt J. Patient and provider barriers to colorectal cancer screening in the primary care safetynet. Prev Med 2004;39:56-63.

43. Montano D, Phillips WR, Kasprzyk D. Explaining physician rates of providing flexible sigmoidoscopy. Cancer Epidemiol Biomarkers Prev 2000;9:665-9.

44. Montano DE, Manders DB, Phillips WR. Family physician beliefs about cancer screening. Development of a survey instrument. J Fam Pract 1990;30: 313-9.

45. Vernon SW. Participation in colorectal cancer screening: a review. J Natl Cancer Inst 1997;89: $1406-22$.

46. Gross CP, Andersen MS, Krumholz HM, McAvay GJ, Proctor D, Tinetti ME. Relation between Medicare screening reimbursement and stage at diagnosis for older patients with colon cancer. JAMA 2006; 296:2815-22. 